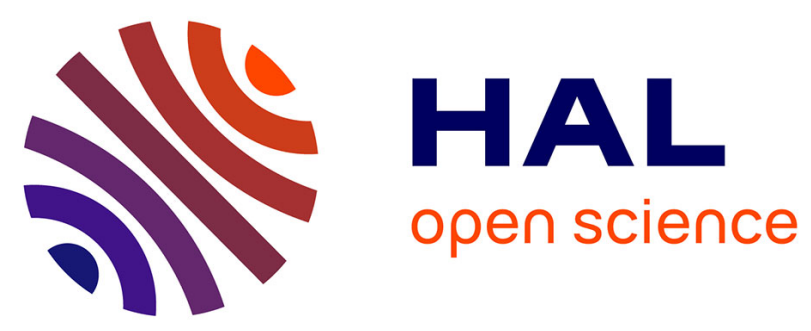

\title{
Phylogenetics and population genetics of the Eurasian parasitoid Macrocentrus cingulum based on mitochondrial and nuclear loci
}

\author{
Benjamin Pelissié, Sergine Ponsard, Denis D. Bourguet, Gael G. Kergoat
}

\section{To cite this version:}

Benjamin Pelissié, Sergine Ponsard, Denis D. Bourguet, Gael G. Kergoat. Phylogenetics and population genetics of the Eurasian parasitoid Macrocentrus cingulum based on mitochondrial and nuclear loci. Entomologia Experimentalis et Applicata, 2012, 145 (1), pp.1-14. 10.1111/j.15707458.2012.01307.x . hal-02650544

\section{HAL Id: hal-02650544 \\ https://hal.inrae.fr/hal-02650544}

Submitted on 12 Aug 2020

HAL is a multi-disciplinary open access archive for the deposit and dissemination of scientific research documents, whether they are published or not. The documents may come from teaching and research institutions in France or abroad, or from public or private research centers.
L'archive ouverte pluridisciplinaire HAL, est destinée au dépôt et à la diffusion de documents scientifiques de niveau recherche, publiés ou non, émanant des établissements d'enseignement et de recherche français ou étrangers, des laboratoires publics ou privés.

\section{(ㅇ)(1) $\$$}

Distributed under a Creative Commons Attribution - NonCommerciall 4.0 International 


\title{
Phylogenetics and population genetics of the Eurasian parasitoid Macrocentrus cingulum based on mitochondrial and nuclear loci
}

\author{
Benjamin Pélissié $^{1 *}$, Sergine Ponsard ${ }^{2}$, Denis Bourguet ${ }^{1} \&$ Gael J. Kergoat $^{1}$ \\ ${ }^{1}$ INRA - UMR CBGP (INRA, IRD, CIRAD, Montpellier SupAgro), Campus de Baillarguet, Montferrier-sur-Lez 34988, \\ France, and ${ }^{2} C N R S$ and Université de Toulouse, UMR 5174, Laboratoire Evolution \& Diversité Biologique, \\ 118 route de Narbonne, Toulouse 31062 , France
}

Key words: biological control, maize, Ostrinia, Bayesian analysis, haplotype networks, host-parasite interactions, ecological speciation, geographical polymorphism, Braconidae, Hymenoptera,

Lepidoptera, Crambidae

\begin{abstract}
Specifying species boundaries is often tricky, because advanced biomolecular analyses can reveal that morphologically similar individuals in fact belong to distinct species. This is frequently the case when populations previously considered as a single polyphagous taxon prove to consist of several genetically distinct taxa using different resources, e.g., among insect parasitoids. Macrocentrus cingulum Brischke (Hymenoptera: Braconidae), a parasitoid of the genus Ostrinia (Lepidoptera: Crambidae) feeding on various host plants across the world, is one of them. In Western Europe, M. cingulum has never been found in Ostrinia nubilalis (Hübner) populations feeding on maize, although it heavily parasitizes sympatric Ostrinia scapulalis Walker populations feeding on mugwort. In contrast, it contributes to pest control of Ostrinia furnacalis Guenée feeding on maize in Asia and O. nubilalis feeding on maize in America, suggesting that European and Asian M. cingulum populations might form two distinct taxa. We tested this hypothesis by conducting phylogenetic and population genetic analyses based on two mitochondrial and two nuclear genes, on 97 M. cingulum individuals sampled in Asia, USA, and Europe. Our analyses not only suggest that all sampled M. cingulum probably belong to the same species, but also show a significant genetic differentiation between individuals originating from Europe on the one hand and Asia/USA on the other, which correlates with infestation patterns. Moreover, they show that American specimens are closely related to Asian ones, consistent with historical records about M. cingulum introductions into the USA in the 1920s and 1930s to control expanding O. nubilalis populations. Combining these results with what is known about the evolutionary history within the genus Ostrinia, we offer a candidate evolutionary scenario that is amenable to future empirical testing.
\end{abstract}

\section{Introduction}

Under the scrutiny of advanced genetic and taxonomic tools, many taxa initially described as a single species turn out to actually consist of distinct genetic entities (Bickford et al., 2007). Examples can be found in many taxa (e.g., for herpetofauna, Speybroeck \& Crochet, 2007; for algae, Leliaert et al., 2009; for birds, Speybroeck et al., 2010),

*Correspondence and present address: Benjamin Pélissié, CIRAD, BIOS, UR-106, TA A-50/D, Campus de Baillarguet, 34398 Montpellier Cedex 5, France. E-mail: benjamin.pelissie@gmail.com including arthropods, for instance Hymenoptera (Smith et al., 2006, 2008) and Lepidoptera (Hebert et al., 2004; Burns et al., 2008). More specifically, many species that live in close association with a host - such as phytophagous insects (Berlocher \& Feder, 2002; Drès \& Mallet, 2002; Dyer et al., 2007; Feder \& Forbes, 2010; Matsubayashi et al., 2010) or parasites (De Meeûs et al., 1998; Jousson et al., 2000; McKoy et al., 2005) - were first considered as generalist feeders and later split into several specialized taxa using distinct resources. Strong and highly specific selection pressures from their hosts and/or coevolutionary processes may have favoured their diversification. As a result, even though parasitic insects already 
represent almost half of all described species (Feder \& Forbes, 2010), their diversity is probably still largely underestimated at both specific and infra-specific level (Novotny et al., 2002).

Hymenoptera is one of the most species-rich insect orders (Daly et al., 1998; Feder \& Forbes, 2010). They include many species that parasitize a wide array of host species and are thereby submitted to an even wider diversity of selection pressures. They are often small and sometimes show very little and hardly detectable morphological variation, which increases the probability of cryptic species remaining unnoticed and makes them a particularly tricky group from a taxonomic point of view. The initial suspicion that a number of species are actually complexes of several cryptic species has been confirmed in several studies on parasitic wasps (e.g., Atanassova et al., 1998; Kankare et al., 2005; Samara et al., 2008; Smith et al., 2008) though not all (Cronin \& Abrahamson, 2001; Baer et al., 2004; Althoff, 2008).

Species belonging to the genus Macrocentrus (Hymenoptera: Braconidae) live as obligatory parasites of Lepidoptera (van Achterberg, 1993) and are actual or candidate biological control agents against stem or twig borers (Crambidae, Gelechiidae, Pyralidae) and leaf rollers (Tortricidae). Among them, Macrocentrus cingulum Brischke also known as Macrocentrus abdominalis Fabricius (Baker et al., 1949), Macrocentrus grandii Goidanich, or Macrocentrus gifuensis Ashmead (van Achterberg \& Haeselbarth, 1983 ) - naturally occurs in the Palearctic region (from Western Europe to Japan: van Achterberg, 1993) and parasitizes two important maize pests of the genus Ostrinia (Lepidoptera: Crambidae) (Baker et al., 1949). Some records also mention lepidopteran hosts other than Ostrinia spp. (Shenefelt, 1969; He et al., 2000), but a large-scale literature survey found no record of these host species or genera ever being infested by $M$. cingulum in field studies conducted over more than 30 years in Europe and North America, and, to a lesser extent, in Asia (De Nardo \& Hopper, 2004). This survey included 25 Crambidae, 17 Pyralidae, 7 Lymantriidae, 43 Noctuidae, and 17 Nymphalidae species (De Nardo \& Hopper, 2004). Therefore, M. cingulum is considered as a specialist of the genus Ostrinia (Thompson \& Parker, 1928; van Achterberg, 1993; He et al., 2000; De Nardo \& Hopper, 2004). Although considered as a single species distributed worldwide, $M$. cingulum displays strong variations in parasitism success within the genus Ostrinia across its geographical range (Thompson \& Parker, 1928; Baker et al., 1949; Frolov et al., 2007; Pélissié et al., 2010), and more specifically within and between three species: Ostrinia nubilalis (Hübner), Ostrinia scapulalis Walker, both sensu Frolov et al. (2007), and Ostrinia furnacalis Guenée.
Ostrinia nubilalis feeds on maize, Zea mays L. (Poaceae), occurs in Europe, and has been introduced accidentally into North America (see below) at the beginning of the 20th century (Mutuura \& Munroe, 1970). Ostrinia furnacalis also feeds on maize and ranges over Eastern Asia (China, Japan, Korea, Philippines, Vietnam) and Australia (Mutuura \& Munroe, 1970), with no or very little overlap with O. nubilalis. Finally, O. scapulalis feeds on a variety of host plants including mugwort, Artemisia vulgaris L. (Asteraceae), hop, Humulus lupulus L., and hemp, Cannabis sativa L. (both Cannabaceae). Its geographical range spans all northern Eurasia, so that it is largely sympatric with $O$. nubilalis in Europe and O. furnacalis in Asia (Frolov et al., 2007).

In Europe, M. cingulum heavily parasitizes (up to 75\%) populations of O. scapulalis (Thompson \& Parker, 1928; Thomas et al., 2003; Pélissié et al., 2010). In contrast, it has never been found emerging from $O$. nubilalis, even in areas of sympatry with $O$. scapulalis populations that were heavily parasitized (Pélissié et al., 2010) and/or in populations in which it has been molecularly detected within O. nubilalis larvae (Pélissié et al., 2010), suggesting that both oviposition and larval development may be affected. Not a single adult emerged from 7500 O. nubilalis larvae from 64 populations collected on maize over four successive years in France (Pélissié et al., 2010) or from 1700 O. nubilalis larvae collected in four localities in Spain (Monetti et al., 2003). Moreover, despite a quite extensive search of the European literature about natural enemies of $O$. nubilalis in the last few decades, we could find no record of $M$. cingulum emerging from larvae collected on maize in this area (former Yugoslavia: Manojlovic, 1984a,b, 1989; France: Grenier et al., 1990; Hungary: Dolinka, 1974; Italy: Maini, 1973; Platia \& Maini, 1973; Romania: Perju, 2005; western Russia: Frolov et al., 1982).

In contrast, $M$. cingulum does parasitize $O$. furnacalis feeding on maize (Baker et al., 1949; He et al., 2000). It also emerges from Ostrinia larvae collected on various host plants - including mugwort - in China and in Japan (J Tabata, D Bourguet \& S Ponsard, unpubl.). Although in those cases the exact Ostrinia host species could not be determined, the host plant species, as well as population genetics studies conducted on Ostrinia larvae collected from the same location and the same plants on the same date (D Bourguet, R Streiff \& S Ponsard, unpubl.) strongly suggest that they were $O$. scapulalis, O. orientalis, or $O$. narynensis, all of which Frolov et al. (2007) propose to synonymize with $O$. scapulalis.

Ostrinia nubilalis, as well as $M$. cingulum, have only recently been introduced into North America (in the 1910s and 1920s, respectively; Thompson \& Parker, 1928), the former accidentally and the latter willingly to control 
it. In this area, maize is infested by O. nubilalis, whereas $O$. scapulalis is absent, and only two other, phylogenetically more distant, Ostrinia species are present: Ostrinia penitalis (Grote) and Ostrinia obumbratalis (Lederer) (Mutuura \& Munroe, 1970). At least O. nubilalis and $O$. penitalis are parasitized by M. cingulum in USA (Baker et al., 1949), no study having dealt with parasitism on O. obumbratalis to our knowledge.

Thus, western Europe is the only known area where $M$. cingulum is present but unable to develop in an Ostrinia species feeding on maize - in this case O. nubilalis - even though it is locally abundant. There is little chance of this being due to scarcity of observations, as $O$. nubilalis natural enemies have been thoroughly studied over the past few decades, due notably to its pest status. An appealing hypothesis to explain this intriguing pattern is that European, Asian, and American populations of M. cingulum, although morphologically similar (Baker et al., 1949; van Achterberg \& Haeselbarth, 1983; He et al., 2000), belong to distinct taxa differing in their abilities to complete their life cycle in Ostrinia populations feeding on maize. To explore this hypothesis, we assessed and compared the molecular diversity of $M$. cingulum populations sampled in Europe, Asia, and USA, using mitochondrial and nuclear DNA markers.

\section{Materials and methods}

\section{Taxon sampling}

Macrocentrus cingulum - pupae or adults - were reared from O. nubilalis larvae sampled in the field and preserved in $90 \%$ ethanol before DNA extraction. As M. cingulum is polyembryonic, we either extracted the DNA from one single larva, or pooled several adults of the same sex in a single DNA extract. The geographical origin, host plant on which Ostrinia larva were collected, putative Ostrinia host species, date of sampling, and method for DNA extraction of the $97 \mathrm{M}$. cingulum samples analysed in this study, are given in Table 1.

As an outgroup for building phylogenetic trees, we used a specimen from a congeneric species, Macrocentrus sylvestrellae (van Achterberg, 2001) (kindly provided by $\mathrm{H}$ Jactel, INRA, France) reared from a larva of the pine stem borer Dioryctria sylvestrella (Ratzeburg) collected in south-western France.

\section{DNA sequencing}

Genomic DNA was extracted using the DNeasyTissue Kit (Qiagen,Veulo,The Netherlands). For each sample, we amplified sequences of two mitochondrial coding regions: part of the cytochrome b (Cyt b) gene, using primers CB-J-10933 and CB-N-11367 (Simon et al., 1994), and part of the cytochrome oxidase subunit I (COI) gene, using primers Lco1490 and Hco2198 (Folmer et al., 1994). In addition, we amplified (by direct amplification) partial sequences of two nuclear genes: the internal transcribed spacer 2 (ITS2), using primers FcM and B1D (Ji et al., 2003), and a region of the elongation factor 1 subunit alpha F2 (EF1a-F2), using primers EF1A1F and EF1A1R (Belshaw \& Quicke, 1997). For EF1a-F2, both coding (exons) and non-coding (introns) regions were sequenced. Standard cycling conditions were $5 \mathrm{~min}$ at $96{ }^{\circ} \mathrm{C}$ followed by 35 cycles of $1 \mathrm{~min}$ at $96^{\circ} \mathrm{C}, 1 \mathrm{~min}$ at $50{ }^{\circ} \mathrm{C}$ for Cyt b and ITS2, $47^{\circ} \mathrm{C}$ for COI, and $47-52{ }^{\circ} \mathrm{C}$ for EF1a-F2, $90 \mathrm{~s}$ at $72{ }^{\circ} \mathrm{C}$, and a final step at $72{ }^{\circ} \mathrm{C}$ for $7 \mathrm{~min}$. The PCR products were directly sequenced in both directions using BigDye v3.1 sequencing kits and Applied 3730xl sequencers. The new sequence data generated in this study were deposited in GenBank, under accession numbers HQ177097 to HQ178683.

All sequence alignments were performed using ClustalX v1.83 (Thompson et al., 1997) with default settings. ITS2 sequences proved strictly invariable across all samples and were thus not used in further analyses. Cyt b and COI alignments revealed no gaps. One gap corresponding to a supplementary position only found in the outgroup species M. sylvestrellae was present in the EF1a-F2 gene. Alignment of EF1a-F2 sequences also showed eight heterozygous positions, which were coded using the IUPAC nucleotide ambiguity codes (e.g., Sota \& Vogler, 2003). After alignment, the combined sequence was $1694 \mathrm{bp}$ long: the COI region (668 characters), the Cyt $b$ region (386 characters), and the intron region of the EF1a-F2 gene (640 characters). For the latter, the two coding regions were situated between positions 1-119 and 337615 , respectively.

\section{Genetic diversity and genetic differentiation}

Genetic diversity was assessed using DNASP v5.10 (Librado \& Rozas, 2009) to estimate haplotype $(\mathrm{H})$ and nucleotide $(\pi)$ diversity. The outgroup species M. sylvestrellae was excluded from these analyses. To take into account the information carried by heterozygous sites in the EF1a-F2 gene, phase at linked loci was inferred using the PHASE algorithm (Stephens et al., 2001; Stephens \& Donnelly, 2003) implemented in DNASP, which uses a coalescence-based Bayesian method to reconstruct haplotypes from genotypes (Stephens et al., 2001). In addition, the software PAUP* v4.0b10 (Swofford, 2003) was used to estimate mean sequence divergence among populations.

The level of genetic differentiation between taxa of distinct geographical origins (American, Asian, or European) was assessed for each gene and for the two mitochondrial genes together (mitochondrial compartment) 
Table 1 Characteristics of the 97 Macrocentrus cingulum used in this study. All specimens originated from diapausing Ostrinia spec. larvae collected on their host plants. The host plants are given in the last column: maize (Zea mays), rumex (Rumex spec.), xanthium (Xanthium spec.), mugwort (Artemisia vulgaris), foxtail bristlegrass (Setaria italica), and sunflower (Helianthus annuus)

\begin{tabular}{|c|c|c|c|c|c|c|c|}
\hline \multirow[b]{2}{*}{ Name } & \multirow{2}{*}{$\begin{array}{l}\text { Life cycle } \\
\text { stage }\end{array}$} & \multirow{2}{*}{$\begin{array}{l}\text { Extraction } \\
\text { method }^{1}\end{array}$} & \multicolumn{5}{|l|}{ Sampling } \\
\hline & & & Date & Continent & Country & Location & Host plant \\
\hline USA751-6, USA771-6 & $\begin{array}{r}\text { Female } \\
\text { adult }\end{array}$ & Q & na & America & USA & $\begin{array}{l}\text { Rosemount, } \\
\text { MN }\end{array}$ & Z. mays \\
\hline USA761-3, USA781-4 & $\begin{array}{l}\text { Male } \\
\text { adult }\end{array}$ & Q & na & America & USA & $\begin{array}{l}\text { Rosemount, } \\
\text { MN }\end{array}$ & Z. mays \\
\hline ASI31 & Pupa & Q & 2005 & Asia & China & $\begin{array}{l}\text { Beijing } \\
\quad \text { (Langfang) }\end{array}$ & Z. mays \\
\hline ASI33 & Pupa & Q & 2005 & Asia & China & $\begin{array}{l}\text { Beijing (Rian } \\
\text { Shan Jian) }\end{array}$ & Z. mays \\
\hline ASI $20-4$ & Adult & Q & 2005 & Asia & China & Shandung & Z. mays \\
\hline $\begin{array}{l}\text { ASI30, ASI32, ASI34, ASI36, ASI37, } \\
\text { ASI39 }\end{array}$ & Pupa & Q & 2005 & Asia & China & Shanghaï & Z. mays \\
\hline ASI11, ASI15 & Pupa & Q & 2005 & Asia & Japan & $\begin{array}{l}\text { Akigawa, } \\
\text { Tokyo Pref. }\end{array}$ & A. vulgaris \\
\hline ASI13 & Pupa & Q & 2005 & Asia & Japan & $\begin{array}{l}\text { Akigawa, } \\
\text { Tokyo Pref. }\end{array}$ & $\begin{array}{l}\text { Rumex } \\
\text { spec. }\end{array}$ \\
\hline ASI14 & Pupa & Q & 2005 & Asia & Japan & $\begin{array}{l}\text { Akigawa, } \\
\text { Tokyo Pref. }\end{array}$ & $\begin{array}{l}\text { Xanthium } \\
\text { spec. }\end{array}$ \\
\hline ASI16, ASI17 & Pupa & Q & 2005 & Asia & Japan & $\begin{array}{l}\text { Akigawa, } \\
\text { Tokyo Pref. }\end{array}$ & Z. mays \\
\hline ASI47-60 & Adult & Q & 2001 & Asia & Japan & $\begin{array}{l}\text { Higashi, Tokyo } \\
\text { Pref. }\end{array}$ & Z. mays \\
\hline ASI1-7 & Adult & Q & 2005-2006 & Asia & Japan & $\begin{array}{l}\text { Kannondai, } \\
\text { Ibaraki Pref. }\end{array}$ & S. italica \\
\hline ASI67 & Adult & Q & 2006 & Asia & Japan & $\begin{array}{l}\text { Moriya, Ibaraki } \\
\text { Pref. }\end{array}$ & H. annuus \\
\hline ASI8-10 & Pupa & Q & 2005 & Asia & Japan & $\begin{array}{l}\text { Yawara, Ibaraki } \\
\text { Pref. }\end{array}$ & $\begin{array}{l}\text { Xanthium } \\
\text { spec. }\end{array}$ \\
\hline ASI68 & Adult & Q & 2006 & Asia & Japan & $\begin{array}{l}\text { Akigawa, } \\
\text { Tokyo Pref. }\end{array}$ & $\begin{array}{c}\text { Ambrosia } \\
\text { spec. }\end{array}$ \\
\hline EUR27-9 & Pupa & Q & 2006 & Europe & France & Glisy & A. vulgaris \\
\hline EUR45, EUR46 & Pupa & Q & $2005-2006$ & Europe & France & Glisy & A. vulgaris \\
\hline EUR128, EUR134-6, EUR138, EUR139 & Pupa & $\beta$ me & $2005-2006$ & Europe & France & Houdan & A. vulgaris \\
\hline EUR15-7, EUR19, EUR66 & Pupa & Q & $2004-2005$ & Europe & France & Ile de France & A. vulgaris \\
\hline EUR25 & Pupa & Q & 2004-2005 & Europe & France & Lille & A. vulgaris \\
\hline $\begin{array}{l}\text { EUR4, EUR5, EUR7, EUR8, EUR25, } \\
\text { EUR41, EUR43, EUR44 }\end{array}$ & Pupa & Q & 2004-2005 & Europe & France & Lille & A. vulgaris \\
\hline EUR11-4, EUR61-5 & Pupa & Q & $2004-2005$ & Europe & Germany & Kropp & A. vulgaris \\
\hline
\end{tabular}

Individuals who shared the same information have been pooled in one row.

na $=$ not available.

${ }^{1} \mathrm{Q}$, Qiagen; $\beta \mathrm{me}, \beta$-mercapto-ethanol.

by estimating three distinct test statistics $\left(\mathrm{F}_{\mathrm{ST}}, \mathrm{K}_{\mathrm{ST}^{\star}}\right.$, and $\mathrm{S}_{\mathrm{nn}}$ ) with DNASP. $\mathrm{F}_{\mathrm{ST}}$ is a statistic that measures the diversity of randomly chosen alleles within the same population relative to what is found in the entire geographical sample. The $\mathrm{K}_{\mathrm{ST}^{*}}$ is a test statistic that takes account of the number of nucleotide differences between different haplotypes but does not give much weighting to large numbers of differ- ences (Hudson et al., 1992). $S_{n n}$ is usually referred to as the nearest-neighbour statistic and is a measure of how often the nearest neighbours (in the matrix) of sequences are from the same population in geographical space (Hudson, 2000). Because these three indices are known to be more or less sensitive to specific data set features (such as a low level of genetic diversity or a low sample size), they 
were used in combination to ensure robust detection of differentiation (Morales-Hojas et al., 2008). For each index, a permutation test of 1000 replicates was performed under DNASP to assess the significance of the subdivision parameters.

\section{Haplotype networks}

The phylogenetic reconstructions showed a low number of haplotypes and the genetic analyses indicated a low level of genetic differentiation between populations (see Results). Hence, we might be dealing with genetic diversity at intraspecific, rather than interspecific, level. We therefore also investigated the relationships between the different haplotypes using statistical parsimony networks (Posada \& Crandall, 2001), which are appropriate for data exhibiting low genetic divergence (Zhang \& Hewitt, 2003). Such networks help inferring spatial and historical patterns within and among populations. Haplotype networks were reconstructed separately for the EF1a-F2 gene and for the mitochondrial gene compartment. To take into consideration the information contained in heterozygous sites of the EF1a-F2 gene, the corresponding haplotype network was reconstructed using the haplotypes inferred by the PHASE algorithm (see above). All networks were estimated with a 95\% parsimony connection limit (without the outgroup taxon), using TCS v1.21 (Clement et al., 2000).

\section{Phylogenetic analyses}

To explore a possible conflict between information carried by the mitochondrial and nuclear genes in our data set, we conducted several incongruence length difference (ILD) tests (Farris et al., 1994), as implemented in PAUP*, with 1000 replicates and all invariant characters excluded (Cunningham, 1997).

To estimate the phylogenetic relationships between taxa, we carried out Bayesian inference (BI) analyses using MrBayes v3.12 (Ronquist \& Huelsenbeck, 2003). In all analyses, the sole gap event was treated as missing data whereas heterozygous positions were taken into account. Separate Bayesian analyses were conducted for each gene, as well as for the combined data set.

For BI analyses on the combined data set, five distinct partitioning strategies were used: $\mathrm{P}_{1}$, 'one partition strategy': one single partition for the whole combined data set; $\mathrm{P}_{2}$, 'two partition strategy': one partition for the mitochondrial compartment and one for the nuclear gene; $\mathrm{P}_{3}$, 'three partition strategy': one partition per gene; $\mathrm{P}_{4}$, 'four partition strategy': one partition per codon position for the two mitochondrial genes (Cyt b and COI) plus one partition for the nuclear gene; and $\mathrm{P}_{5}$, 'seven partition strategy': one partition per codon position for Cyt b, one partition per codon position for COI, plus one partition for the nuclear gene. Evolutionary models for each gene or partition were selected using Modeltest v3.06 (Posada \& Crandall, 1998), based on the corrected Akaike's Information Criterion (AIC). Allowing subsets of the data to evolve under different models is expected to increase both phylogenetic accuracy and posterior probabilities estimates (Nylander et al., 2004), although, on the other hand, estimating model parameters on smaller data sets increases the risk of random error (Brandley et al., 2005). In this study, we used the Bayes factor $\left(\mathrm{B}_{\mathrm{F}}\right)$ as an objective criterion to choose between pairs of alternative strategies. The traditional cut-off criterion of $2 \ln \mathrm{B}_{\mathrm{F}} \geq 10$ was used to choose among competing strategies (Brandley et al., 2005). $B_{F}$ values were estimated based on the ratio of the harmonic mean of the likelihoods (sampled from the posterior using the 'sump' option in MrBayes with a specified burn-in period). For all analyses (i.e., separate analyses of each gene and analyses of the combined data set using different partitioning strategies), two independent runs of 10000000 generations were performed. For each run, we used eight Metropolis-coupled chains, with high heating values $(\mathrm{T}=0.8)$, random starting trees, and default priors. Distinct parameters were estimated for each partition under the best-fit substitution models (determined according to the AIC). During the run, the trees and branch lengths were saved every 100 generations -100000 trees were thus saved at the end of each Monte Carlo Markov chain (MCMC) run. We applied a conservative burnin period of 1000000 generations, so we kept the topologies sampled in the last 9000000 generations. For each analysis, results were generated using the pooled tree samples from the stationary phases of the independent runs reached in all cases before generation 1000000 - and the support for each node of this tree was given by clade posterior probability (CPP) estimates. Because Bayesian posterior probabilities are probably less conservative than non-parametric bootstrap values, especially for short internodes (Alfaro et al., 2003; Erixon et al., 2003), only clades with posterior probabilities $>0.9$ were considered as well-supported ones in BI analyses.

Additional analyses were also conducted under parsimony with the software TNT v.1.1 (Goloboff et al., 2008). Initial heuristic searches were carried out using the tree bisection reconnection (TBR) algorithm ('traditional search' option in TNT), with random starting trees, 100 random-addition replicates, and a 'MaxTrees' value of 1000 . Additional analyses were conducted using sectorial searches with random sectorial searches (RSS) and consensus-based sectorial searches (CSS) (Goloboff, 1999), with the options for tree ratchet, tree drifting, and tree fusing (Goloboff, 1999) selected ('new technology search' option in TNT), 100 random-addition replicates and a 
'MaxTrees' value of 1000 . For each analysis, 1000 non-parametric bootstrap replications were performed (standard sample with replacement).

\section{Phylogenetic hypotheses testing}

To know whether or not European, Asian, and American populations of $M$. cingulum should be considered as sister groups, we tested for both the possible monophyly of populations from each continent and for the possible reciprocal monophyly of some of them using the Shimodaira Hasegawa (SH) test (Shimodaira \& Hasegawa, 1999). Following Goldman et al. (2000), we tested for the difference between an optimal tree (resulting from an unconstrained analysis based on maximum likelihood) and a constrained tree (in which specific individuals are constrained to be monophyletic). Three distinct tests were performed: (1) all American individuals constrained to monophyly; (2) all Asian individuals constrained to monophyly; and (3) all American and Asian individuals constrained to monophyly on the one hand and all European individuals constrained to monophyly on the other (test for reciprocal monophyly). All SH tests were carried out with PAUP* (RELL method; 1000 replicates).

\section{Results}

Genetic diversity and genetic differentiation

The ILD tests revealed no significant incongruence between $\mathrm{COI}$ and Cyt b, therefore we also performed supplementary analyses considering them as a single evolutionary unit (mitochondrial compartment). The number of distinct haplotypes was 14 for the EF1a-F2 gene and 32 for the mitochondrial compartment (Table 2).

On average, the distance between haplotypes was low, especially for EF1a-F2. Nevertheless, none of the mitochondrial haplotypes found in European populations were ever found in Asian or American populations, and three and two EF1a-F2 haplotypes found in European populations were also found in Asian and American populations, respectively. The number of shared haplotypes was higher or equal between American and Asian populations (two for the mitochondrial compartment, three for EF1a-F2; Table 3). The American population displayed both the highest haplotype diversity (up to 0.83 , depending on gene, vs. 0.71 and 0.72 for the European and Asian populations, respectively; Table 2) and the highest nucleotide diversity (up to 0.0072 vs. 0.0022 and 0.0031 for the European and Asian populations, respectively; Table 2).

A strong and highly significant $(\mathrm{P}<0.0001$ for all comparisons) genetic structure between European populations and their Asian or American counterparts was consistently found for mitochondrial genes as well as for EF1a-F2 $\left(\mathrm{F}_{\mathrm{ST}}\right.$, $\mathrm{K}_{\mathrm{ST}^{\star}}$, and $\mathrm{S}_{\mathrm{nn}}$ values ranged $0.45-0.79,0.28-0.55$, and $0.82-1$, respectively; Table 3 ). We also found a significant genetic structure for both the mitochondrial compartment and the nuclear gene between the Asian and American populations, although the genetic differentiation was lower between these two populations than between any of them and the European population $\left(\mathrm{F}_{\mathrm{ST}}, \mathrm{K}_{\mathrm{ST}^{*}}\right.$, and $\mathrm{S}_{\mathrm{nn}}$ equalled $0.40,0.20$, and 0.88 for the mitochondrial compartment and 0.05, 0.03, and 0.69 for EF1a-F2; Table 3).

\section{Haplotype networks}

For clarity and because both COI and Cyt b reflect the history of the same evolutionary unit (as confirmed by the ILD test, see below), we display only two networks, one based on the combination of both mitochondrial genes and one based only on EF1a-F2 sequences (Figure 1). Due to the lower number of haplotypes $(\mathrm{n}=14)$, the network based on nuclear sequences was less reticulated than that based on mitochondrial sequences. Nevertheless, both networks exhibited essentially the same patterns. First, most European haplotypes were grouped together. Second, the Asian population contained the most frequently sampled and best-connected haplotype (Crandall \& Templeton, 1993), suggesting that it might represent the ancestral population. Third, American individuals were not completely clustered, some of them sharing Asian haplotypes.

Table 2 Genetic diversity estimates for each set of populations for each gene

\begin{tabular}{|c|c|c|c|c|c|c|c|c|c|c|c|c|}
\hline \multirow[b]{2}{*}{ Gene } & \multicolumn{4}{|c|}{ European populations } & \multicolumn{4}{|c|}{ Asian populations } & \multicolumn{4}{|c|}{ American population } \\
\hline & $\mathrm{N}$ & $\mathrm{n}$ & $\mathrm{H}$ & $\pi$ & $\mathrm{N}$ & $\mathrm{n}$ & $\mathrm{H}$ & $\pi$ & $\mathrm{N}$ & $\mathrm{n}$ & $\mathrm{H}$ & $\pi$ \\
\hline $\mathrm{CO} 1$ & 33 & 8 & 0.69 & 0.0017 & 45 & 11 & 0.52 & 0.0032 & 19 & 7 & 0.66 & 0.0056 \\
\hline Cyt b & 33 & 4 & 0.53 & 0.0022 & 45 & 7 & 0.48 & 0.0032 & 19 & 7 & 0.74 & 0.0073 \\
\hline Mitochondrial compartment & 33 & 9 & 0.71 & 0.0019 & 45 & 14 & 0.72 & 0.0032 & 19 & 11 & 0.83 & 0.0062 \\
\hline EF1a-F2 & 66 & 3 & 0.52 & 0.0008 & 90 & 10 & 0.51 & 0.0012 & 38 & 7 & 0.74 & 0.0025 \\
\hline
\end{tabular}

Note that for the EF1a-F2 gene, the N values take into account haplotype reconstructions using the PHASE algorithm. N, no. individuals/ alleles analysed; $\mathrm{n}$, no. haplotypes; $\mathrm{H}$ and $\pi$, haplotype and nucleotide diversity, respectively. 
Table 3 Genetic differentiation values estimated for each pair of continents of origin and for each locus, and number of shared haplotypes (s.h.)

\begin{tabular}{|c|c|c|c|c|c|c|c|c|c|c|c|c|}
\hline \multirow[b]{2}{*}{ Gene } & \multicolumn{4}{|c|}{ European vs. Asian populations } & \multicolumn{4}{|c|}{ Asian vs. American populations } & \multicolumn{4}{|c|}{ European vs. American populations } \\
\hline & s.h. & $\mathrm{F}_{\mathrm{ST}}$ & $\mathrm{K}_{\mathrm{ST}^{*}}$ & $\mathrm{~S}_{\mathrm{nn}}$ & s.h. & $\mathrm{F}_{\mathrm{ST}}$ & $\mathrm{K}_{\mathrm{ST}^{*}}$ & $\mathrm{~S}_{\mathrm{nn}}$ & s.h. & $\mathrm{F}_{\mathrm{ST}}$ & $\mathrm{K}_{\mathrm{ST}^{*}}$ & $\mathrm{~S}_{\mathrm{nn}}$ \\
\hline $\mathrm{CO} 1$ & 0 & $0.716^{\star * *}$ & $0.460^{\star * *}$ & $1.0^{* * *}$ & 2 & $0.364^{\star \star \star *}$ & $0.226^{* * *}$ & $0.848^{\star \star \star}$ & 0 & $0.505^{\star * *}$ & $0.314^{\star \star \star}$ & $0.981^{* * *}$ \\
\hline Cyt b & 0 & $0.792^{\star * *}$ & $0.549^{\star * *}$ & $1.0^{* * *}$ & 2 & $0.454^{* * *}$ & $0.264^{* * *}$ & $0.854^{\star * \star}$ & 0 & $0.677^{\star * *}$ & $0.434^{\star * \star}$ & $1.0^{* * *}$ \\
\hline $\begin{array}{l}\text { Mitochondrial } \\
\text { compartment }\end{array}$ & 0 & $0.752^{\star * *}$ & $0.437^{\star * *}$ & $1.0^{* * *}$ & 2 & $0.404^{\star * *}$ & $0.204^{\star * *}$ & $0.875^{\star * *}$ & 0 & $0.598^{* * *}$ & $0.324^{\star * *}$ & $1.0^{* * *}$ \\
\hline EF1a-F2 & 3 & $0.544^{\star * *}$ & $0.331^{\star * *}$ & $0.83^{\star * *}$ & 3 & $0.052^{* *}$ & $0.031^{\star}$ & $0.691^{\star * *}$ & 2 & $0.447^{\star * *}$ & $0.277^{\star * *}$ & $0.903^{\star * *}$ \\
\hline
\end{tabular}

$\mathrm{P}$-values for each of these analyses were calculated using 1000 permutations.

${ }^{*} 0.01<\mathrm{P}<0.05 ;{ }^{* *} 0.001<\mathrm{P}<0.01 ;{ }^{* * *} \mathrm{P}<0.001$.

\section{Phylogenetic analyses and phylogenetic hypotheses testing}

There were 1054 alignment positions in the mitochondrial data set, 27 of which were parsimony informative (24 when excluding the outgroup taxon). Only 7 of 640 alignment positions were parsimony informative in the nuclear data set (six when excluding the outgroup taxon). Unsurprisingly, the ILD test found no significant incongruence between the two mitochondrial genes $(P>0.05)$, as they belong to the same evolutionary unit. In contrast, a significant incongruence was detected between mitochondrial and nuclear compartments $(\mathrm{P}=0.01)$.

For each gene (or molecular compartment), the general time reversible model (GTR; Yang, 1994) was identified as the most appropriate substitution model according to the corrected AIC. The comparison of $\mathrm{B}_{\mathrm{F}}$ values identified $\mathrm{P}_{4}$ (i.e., one partition per codon position for the two mitochondrial genes plus one partition for the nuclear gene) as the optimal partitioning strategy. Overall, the topologies resulting from the separate $\mathrm{BI}$ analyses of the three genes were unresolved and weakly supported (only three nodes were supported by CPP values $>0.9$ ). However, most sampled individuals were genetically distinct and clustered by geographical origin, especially in the trees based on COI and Cyt b. In those topologies, one clade including European specimens and one or several clades including Asian and/or American specimens were consistently recovered.

Analyses of the combined data set under BI yielded similar topologies (with slight variations in branching order). Compared with those based on single genes, the topology (Figure 2) based on the combined data was much more resolved and better supported (15 nodes with CPP values $>0.9$ ). In the resulting tree, almost all specimens were clustered by geographical origin. This was especially true for the European specimens, which constituted a monophyletic group nested within a larger clade including all the Asian and American specimens. The latter appeared paraphyletic, as the monophyly hypothesis was rejected both for American and for Asian populations ( $\mathrm{SH}$ tests:
$\mathrm{P}=0.044$ and $\mathrm{P}=0.002$, respectively). The $\mathrm{SH}$ test in which European specimens were constrained into a sister group position with another including both the American and the Asian specimens also resulted in rejection of the null hypothesis $(\mathrm{P}=0.023)$, strongly suggesting that these two groups do not exhibit reciprocal monophyly.

In contrast with $\mathrm{BI}$, under parsimony, not only the topologies resulting from the separate analyses but also the topologies resulting from the analysis of the combined data set were mostly unresolved and weakly supported. For the combined data set, 'Traditional search' analyses generated 20 equiparsimonious trees ('MaxTrees' value was fixed to 1000 trees), whereas 'New Technology search' analyses recovered one equiparsimonious tree of the same size. All trees exhibited the following characteristics: length $=257$, consistency index $=0.852$, and retention index $=0.933$. In agreement with $\mathrm{BI}$ analyses, the European group was the only monophyletic group recovered when analysing either the combined data set or the Cyt b data set (although weakly supported in this case; bootstrap values $<30 \%$ ).

\section{Discussion}

\section{Macrocentrus cingulum populations probably belong to a single species worldwide}

Altogether, our results suggest that all $M$. cingulum specimens from Europe, America, and Asia are closely related to each other, and probably part of the same species. First, molecular divergence between European and Asian populations was weak, especially for the nuclear loci. The ITS proved to be monomorphic across all specimens, although it is known to evolve rapidly and to be clearly differentiated between well-established species (Stouthamer et al., 1999), sibling species (Allemand et al., 2002; Alvarez \& Hoy, 2002), and even conspecific populations (Alvarez \& Hoy, 2002) of various hymenopteran parasitoids. Similarly, the EF1a-F2 gene showed a relatively low 


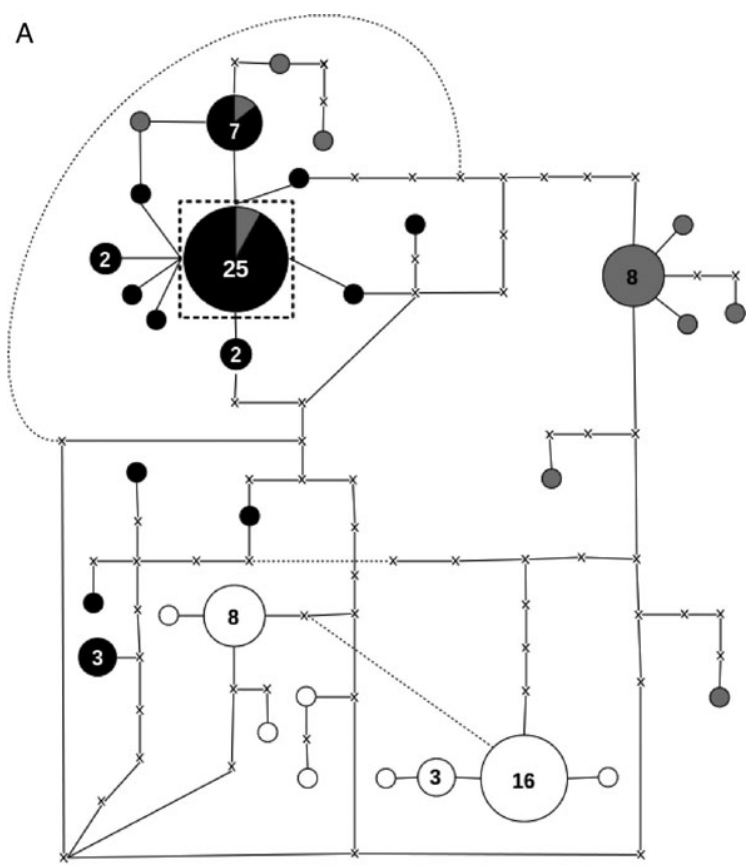

B

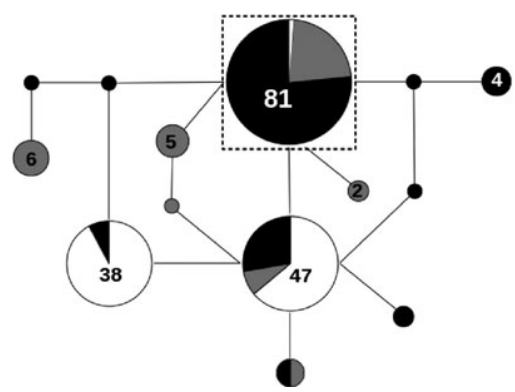

Figure 1 Statistical parsimony haplotype networks based on (A) mitochondrial (COI and Cyt b genes) and (B) nuclear (EF1a-2F gene) compartments. Each circle represents a sampled haplotype and its geographical origin (black: Asia; grey: USA; white: Europe). Black crosses represent hypothetical, nonsampled haplotypes. Circles and black crosses are separated by one mutational step (loops are represented by dotted lines). Circular areas are proportional to the number of sampled individuals sharing the haplotype (specified when $>1$ ). The haplotype most likely to be ancestral (i.e., both the most frequently sampled and the most connected to others) is surrounded by a dotted square.

number of haplotypes $(\mathrm{n}=14)$, two of which were shared among European, Asian, and American populations. In the mitochondrial compartment, we found no shared haplotype between Europe and any of the two other continents, but we still found $<0.5 \%$ mean divergence (i.e., the number of nucleotidic substitutions) between the COI sequences in Asian and European populations. As a comparison, for the same gene, Danforth et al. (1998) found a minimum of $4 \%$ divergence between two cryptic species, Halictus ligatus Say and Halictus poeyi Lepeletier, and Kruse \& Sperling (2001) found 1.5-2.5\% divergence between two closely related species, Archips argyrospila Walker and Archips goyerana Kruse.

Second, both haplotype networks were well connected and haplotypes were separated from each other by only few mutations, suggesting that they all belong to the same or very closely related taxa. If individuals belonged to more distant taxa, haplotypes would rather be expected to be scattered in loosely or even disconnected networks (Crandall \& Templeton, 1993). Third, the hypothesis of reciprocal monophyly between, on the one hand, European populations (which formed a well-supported monophyletic group in the selected topologies), and, on the other, Asian/American populations (which were paraphyletic), was rejected. This pattern points to the existence of either one single taxon or two weakly differentiated taxa, rather than two clearly differentiated ones.

\section{Nevertheless, European Macrocentrus cingulum form a distinct clade}

Our results also show that a European clade can be clearly distinguished at both mitochondrial and nuclear loci. This clade only contained European individuals, all of which emerged from Ostrinia larvae collected on mugwort. The European populations also exhibited the strongest indices of genetic differentiation vs. both American and Asian populations, the latter being the most genetically distant. American and Asian populations were also significantly differentiated, but less so than they both were from European populations.

Asian populations appear as ancestral compared with the other M. cingulum populations in our data set, as, in both mitochondrial and nuclear haplotype networks, the most frequently sampled and best-connected haplotype was mainly carried by Asian individuals (Figure 1). Moreover, Asian haplotypes belong to the more 'basal' cluster of the phylogenetic tree (Figure 2) - although the support of the deeper nodes needs to be improved to confirm this conclusion. The American population appeared paraphyletic and mixed with Asian individuals, both in the phylogenetic reconstructions (Figure 2) and in the haplotype networks (Figure 1). In contrast, the monophyletic cluster of European populations remained nested in the 'basal' Asian/American cluster, suggesting that it also derived from the Asian populations, although probably earlier in time than the Rosemount (USA) population did. Therefore, although our study argues - until contradicting evidence - in favour of $M$. cingulum populations being considered as a single species worldwide, it also shows that, within this species, European populations form a group 
Figure 2 Phylogenetic trees of 97 Macrocentrus cingulum individuals corresponding to the result of the partitioned Bayesian inferences. The largest tree corresponds to the analysis carried out using the best partitioning strategy $\left(\mathrm{P}_{4}\right)$. Nodes supported by CPP values $>0.9$ are highlighted with grey circles and represent wellsupported clades in the BI analysis. European and American individuals are figured using italic and bold characters, respectively. In addition, results from the analyses of separate data sets are figured for the three genes. In the corresponding trees, individuals from the USA are represented using thick lines, whereas European specimens are indicated by blurred lines (normal lines are used for Asian specimens).

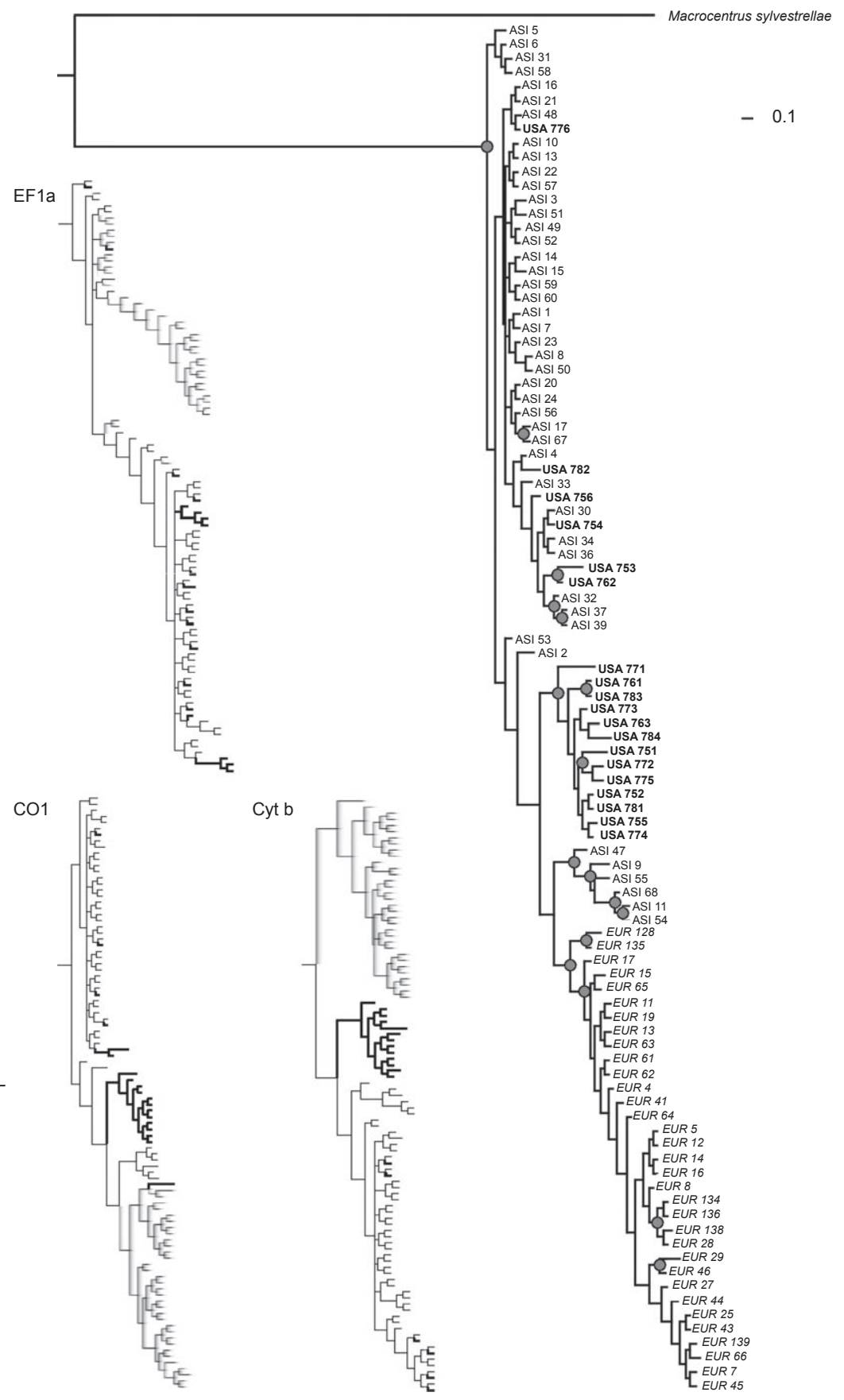

1989; Grenier et al., 1990; Monetti et al., 2003; Thomas et al., 2003; Perju, 2005; Pélissié et al., 2010), although it is found sometimes at high rates in $O$. scapulalis larvae feeding on mugwort and hop (Thomas et al., 2003; Pélissié et al., 2010). In Asia, M. cingulum can parasitize (possibly several species of) Ostrinia developing on a variety of host plants including mugwort and maize - as well as Xanthium spec., Ambrosia spec., Helianthus spec., Setaria italica (L.)

\section{Genetic differentiation correlates with parasitization patterns}

Despite extensive investigations, $M$. cingulum has never been observed emerging from $O$. nubilalis feeding on maize in Europe (Maini, 1973; Platia \& Maini, 1973; Dolinka, 1974; Frolov et al., 1982; Manojlovic, 1984a,b, 
P. Beauv., Rumex spec., and possibly others -, and we found no evidence for the existence of a separate, host plant-related M. cingulum taxon (analyses not shown). Indeed, our reconstructions did not cluster individuals collected in Asia on mugwort or other non-maize plants any closer to the European specimens (also collected on mugwort) than to Asian specimens collected on maize. In contrast, we did find evidence for genetic divergence between European and Asian M. cingulum populations (see above). Isolation by distance may contribute to this divergence, as the closest pair of European and Asian specimens was sampled at a distance of ca. $9000 \mathrm{~km}$. Isolation by distance has been documented in other hymenopteran parasitoids at similarly large (e.g., Grillenberger et al., 2009) or even smaller geographical scale (e.g., Anton et al., 2007; Althoff, 2008). However, the influence of geographical distances on genetic diversity must be moderate here, as we did not detect any differentiation between specimens sampled in China and Japan, which are separated by some $1000-1500 \mathrm{~km}$ : all Asian individuals were mixed in the phylogenetic reconstructions regardless of geographical origin (data not shown). The genetic differentiation between our Asian and European samples could thus be correlated with a difference between Asian and European populations of M. cingulum in their ability to parasitize Ostrinia populations feeding on maize, rather than or in addition to isolation by distance.

\section{An evolutionary scenario with three testable predictions}

Our results, along with historical records, allow us to build an evolutionary scenario that could explain the intriguing differences between $M$. cingulum infestation patterns in Ostrinia populations feeding on maize vs. mugwort in Europe, and Ostrinia populations on maize across the world. At this stage, this scenario is simply compatible with our data. Nevertheless, it is falsifiable in the Popperian sense, as it implies at least two predictions that can be tested in future experiments.

The centre of highest diversity - and probably the centre of origin - of the genus Ostrinia is thought to be eastern Asia (eastern China and Japan; Mutuura \& Munroe, 1970), where a variety of Ostrinia species are found on a variety of host plants. Ostrinia scapulalis and $O$. nubilalis are the two main species present in Europe, and, according to Kim et al.'s (1999) phylogeny, they are the two most recently diverged species within the genus Ostrinia. The fact that $O$. nubilalis is not documented eastwards of Xinjiang (Wang et al., 1995; Xu et al., 1998) suggests that the divergence between $O$. scapulalis and O. nubilalis may have occurred in central/western Asia or Europe, rather than in eastern Asia. Given that the major current host plant of $O$. scapulalis - mugwort - is native from Eurasia, whereas
O. nubilalis' main host - maize - is not, it is parsimonious to assume that the ancestral Ostrinia species used to feed on mugwort, a common weed widely distributed across the entire continent. The divergence between $O$. nubilalis and $O$. scapulalis may then have been either triggered or followed by a host shift of $O$. nubilalis on maize (Malausa et al., 2005, 2007). Meanwhile, in eastern Asia, O. furnacalis must have shifted or differentiated on maize after this crop was introduced in its distribution range, around 500 years ago.

In this framework, M. cingulum as a species, and/or its close association with the genus Ostrinia, might have originated in eastern Asia. Later, the ancestral species from which $O$. scapulalis and O. nubilalis diverged must have extended westwards where other Ostrinia spp. were rare or absent. Macrocentrus cingulum may have followed it, while losing certain 'generalist traits' that allow it to parasitize various Ostrinia species on various host plants in Asia, as it was exposed to selection pressures exerted by only one particular host. When $O$. nubilalis diverged from $O$. scapulalis and shifted on maize, $M$. cingulum populations that had evolved only or mostly on $O$. scapulalis for many generations may no longer have been 'generalist enough' to parasitize this new host. In contrast, more generalist and diverse East-Asian $M$. cingulum populations were able to 'follow' O. furnacalis when it started feeding on maize.

The fact that the American M. cingulum population analysed here is closer to the Asian than to the European ones fits well into this scenario. Indeed, several attempts were made to introduce $M$. cingulum into various regions of the USA between 1926 and 1940 (Thompson \& Parker, 1928; Baker et al., 1949; Hudon et al., 1989; Sked \& Calvin, 2005). These introductions were conducted both with individuals collected in Asia - probably from $O$. furnacalis larvae - and in Europe - probably from O. scapulalis larvae. Unfortunately, the origin of the released parasitoids in each locality was not always precisely recorded, and not all introductions were subjected to a local follow-up to see if self-sustaining populations had established. Nevertheless, there does seem to be a tendency in Baker et al.'s (1949) report for introductions carried out with Asian populations to be the most or possibly even the only successful ones. As American O. nubilalis populations are of recent European origin (Hudon et al., 1989), it would not be surprising if European M. cingulum, which appear unable to develop on O. nubilalis in Europe, were also unable to do so in America. In contrast, the Asian M. cingulum parasitizing a variety of Ostrinia spp. on a variety of host plants including maize in Asia may have retained generalist traits that enabled them to parasitize O. nubilalis on maize when introduced into America. 
The high haplotype diversity of the unique American population we analysed (comparable to that of our entire Asian or entire European samples; Table 2) is rather unexpected in this scenario, as introductions usually rather cause genetic bottlenecks. Moreover, most Asian M. cingulum introduced into America seem to have originated from Korea and Japan, a relatively small geographical area (Baker et al., 1949). This high diversity might partly be due to a mixture of Asian and European haplotypes: although our American population did not share a single haplotype with our European populations - whereas it did with Asian ones -, additional analyses may reveal the existence of shared European-American haplotypes in Rosemount or in other American M. cingulum populations. On the other hand, historical records show that releases of $M$. cingulum into the USA were massive, well spread over the country, and repeated in time: from 1926 to 1940, a total of $416125 \mathrm{M}$. cingulum individuals were released in a total of 80 localities across nine states, from which at least 229423 came from Europe and 85650 came from Asia (Baker et al., 1949). The intensity of the biocontrol effort during 14 years may have been sufficient to account for high genetic diversity in American populations even if they are all of Asian origin.

Three testable predictions emerge from our results. First, most if not all current $M$. cingulum populations in North America must be recently derived from Asian ancestors. This can be checked by analysing further American M. cingulum populations, sampled in localities where this species was introduced in the 1920s and 1930s. Second, Asian M. cingulum, contrary to European populations of the parasitoid, should be able to develop in O. nubilalis feeding on maize in Europe, as they are in America. This can be verified by comparing the ability of $M$. cingulum from Asia and Europe to oviposit and to develop in European $O$. nubilalis on maize, possibly in semi-natural conditions to avoid unwanted introductions. Note that O. furnacalis is known to be able, to some degree, to prevent Asian M. cingulum eggs from developing until adult stage by means of specialized haemocytes that encapsulate the egg or early embryo (Hu et al., 2003, 2008). Therefore, knowing that Pélissié et al. (2010) found that European M. cingulum does emerge from $O$. scapulalis but not from O. nubilalis larvae, it seems that it may lack the ability to escape encapsulation by Ostrinia feeding on maize, contrary to Asian and American ones. Another hypothesis (non-reciprocally exclusive with the latter) is that European O. nubilalis may have a stronger ability to encapsulate than O. furnacalis and American O. nubilalis. Both hypotheses can be tested by studying the encapsulation efficiency of American vs. European O. nubilalis larvae of eggs from American (or Asian) vs. European M. cingulum.
Third, whether or not $M$. cingulum from all three continents belong to a single species in the biological sense, as suggested by their low genetic differentiation, is currently being investigated by testing their ability to interbreed. Note that our scenario does not depend crucially on this result, as differences in parasitization patterns in Europe and Asia are possible with or without reproductive isolation. However, in addition to further clarifying the taxonomic status of Asian and European M. cingulum, it will indicate whether or not populations of both origins may have interbred in America over the last century, and whether or not they might do so in Europe in the event of a release for biological control.

Beyond this special case, the recent evolutionary history of the maize/Ostrinia spp./M. cingulum system could not only become an interesting model to study the effects and evolution of tritrophic interactions during range expansions or after species introductions, but also provide important insights into the theory and practise of biological control.

\section{Acknowledgements}

We thank H. Jactel, J. Tabata, C. Hsu, and G. Heimpel for providing some of the specimens used in this study. We also thank A. Loiseau and P. Audiot for their help with molecular biology benchwork, and Abel Bernadou and two anonymous referees for helpful comments on the manuscript. This study was supported by the ANR grant 'Ecologie pour la Gestion des Ecosystèmes et de leurs Ressources' (ECOGER) and by the CNRS grant 'Impact des Biotechnologies dans les Agro-Ecosystèmes'.

\section{References}

van Achterberg C (1993) Revision of the subfamily Macrocentrinae Foerster (Hymenoptera: Braconidae) from the Palaearctic region. Zoologische Verhandelingen 286: 1-110.

van Achterberg C (2001) Macrocentrus sylvestrellae spec. nov. (Hymenoptera: Braconidae: Macrocentrinae), a parasitoid of Dioryctria sylvestrella (Ratzeburg) (Lepidoptera: Pyralidae). Zoologische Mededelingen 75: 79-88.

van Achterberg C \& Haeselbarth E (1983) Revisionary notes on the European species of Macrocentrus Curtis sensu stricto (Hymenoptera: Braconidae). Entomofauna 4: 37-59.

Alfaro ME, Zoller S \& Lutzoni F (2003) Bayes or bootstrap? A simulation study comparing the performance of Bayesian Markov chain Monte Carlo sampling and bootstrapping in assessing phylogenetic confidence. Molecular Biology and Evolution 20: 255-266.

Allemand R, Lemaitre C, Bouletreau M, Vavre F, Nordlander G et al. (2002) Phylogeny of six african Leptopilina species (Hymenoptera: Cynipoidea, Figitidae), parasitoids of Drosophila, with 
description of three new species. Annales de la Société Entomologique de France 38: 319-332.

Althoff DM (2008) A test of host-associated differentiation across the 'parasite continuum' in the tri-trophic interaction among yuccas, bogus yucca moths, and parasitoids. Molecular Ecology 17: 3917-3927.

Alvarez JM \& Hoy MA (2002) Evaluation of the ribosomal ITS2 DNA sequences in separating closely related populations of the parasitoid Ageniaspis (Hymenoptera: Encyrtidae). Annals of the Entomological Society of America 95: 250-256.

Anton C, Zeisset I, Musche M, Durka W, Boomsma JJ \& Settele J (2007) Population structure of a large blue butterfly and its specialist parasitoid in a fragmented landscape. Molecular Ecology 16: 3828-3838.

Atanassova P, Brookes CP, Loxdale HD \& Powell W (1998) Electrophoretic study of five aphid parasitoid species of the genus Aphidius (Hymenoptera: Braconidae), including evidence for reproductively isolated sympatric populations and a cryptic species. Bulletin of Entomological Research 88: 3-13.

Baer CF, Tripp DW, Bjorksten TA \& Antolin MF (2004) Phylogeography of a parasitoid wasp (Diaeretiella rapae): no evidence of host-associated lineages. Molecular Ecology 13: 1859-1869.

Baker WA, Bradley WG \& Clark CA (1949) Biological control of the European corn borer in the United States. USDA Technical Bulletin 938: 1-185.

Belshaw R \& Quicke DLJ (1997) A molecular phylogeny of the Aphidiinae (Hymenoptera: Braconidae). Molecular Phylogenetics and Evolution 7: 281-293.

Berlocher SH \& Feder JL (2002) Sympatric speciation in phytophagous insects: moving beyond controversy? Annual Review of Entomology 47: 773-815.

Bickford D, Lohman DJ, Sodhi NS, Ng PKL, Meier R et al. (2007) Cryptic species as a window on diversity and conservation. Trends in Ecology and Evolution 22: 148-155.

Brandley MC, Schmitz A \& Reeder TW (2005) Partitioned Bayesian analyses, partition choice, and the phylogenetic relationships of scincid lizards. Systematic Biology 54: 373-390.

Burns JM, Janzen DH, Hajibabaei M, Hallwachs W \& Hebert PDN (2008) DNA barcodes and cryptic species of skipper butterflies in the genus Perichares in Area de Conservacion Guanacaste, Costa Rica. Proceedings of the National Academy of Sciences of the USA 105: 6350-6355.

Clement M, Posada D \& Crandall K (2000) TCS: a computer program to estimate gene genealogies. Molecular Ecology 9: 1657-1660.

Crandall KA \& Templeton AR (1993) Empirical tests of some predictions from coalescent theory with applications to intraspecific phylogeny reconstruction. Genet 134: 959-969.

Cronin JT \& Abrahamson WG (2001) Do parasitoids diversify in response to host-plant shifts by herbivorous insects? Ecological Entomology 26: 347-355.

Cunningham CW (1997) Can three incongruence tests predict when data should be combined? Molecular Biology and Evolution 14: 733-740.
Daly HV, Doyen JT \& Purcell AH, III (1998) Introduction to Insect Biology and Diversity, 2nd edn. Oxford University Press, Oxford, UK.

Danforth BN, Mitchell PL \& Packer L (1998) Mitochondrial DNA differentiation between two cryptic Halictus (Hymenoptera: Halictidae) species. Annals of the Entomological Society of America 91: 387-391.

De Meeûs T, Michalakis Y \& Renaud F (1998) Santa rosalia revisited: or why are there so many kinds of parasites in the garden of earthly delights? Parasitology Today 14: 10-13.

De Nardo EAB \& Hopper KR (2004) Using the literature to evaluate parasitoid host ranges: a case study of Macrocentrus grandii (Hymenoptera: Braconidae) introduced into North America to control Ostrinia nubilalis (Lepidoptera: Crambidae). Biological Control 31: 280-295.

Dolinka B (1974) Pest control in corn on the Danube plain illustrated by Hungarian examples. Report of the VIth Conference of the International Working Group on the European Corn Borer, St Paul/Minneapolis, MN, USA, pp. 35-41.

Drès M \& Mallet J (2002) Host races in plant-feeding insects and their importance in sympatric speciation. Philosophical Transactions of the Royal Society B 357: 471-492.

Dyer LA, Singer MS, Lill JT, Stireman JO, Gentry GL et al. (2007) Host specificity of Lepidoptera in tropical and temperate forests. Nature 448: 696-700.

Erixon P, Svennblad B, Britton T \& Oxelman B (2003) Reliability of Bayesian posterior probabilities and bootstrap frequencies in phylogenetics. Systematic Biology 52: 665-673.

Farris JS, Källersjö M, Kluge AG \& Bult C (1994) Testing significance of incongruence. Cladistics 10: 315-319.

Feder JL \& Forbes AA (2010) Sequential speciation and the diversity of parasitic insects. Ecological Entomology 35: 67-71.

Folmer RHA, Folkers PJM, Kaan A \& Jonker AJ (1994) Secondary structure of the single-stranded DNA binding protein encoded by filamentous phage Pf3 as determined by NMR. European Journal of Biochemistry 224: 663-676.

Frolov AN, Vilkova NA, Shapiro ID \& Khromenko AS (1982) Role of Host Plants in Formation of Trophic Relations of Stem Borers Ostrinia spp. and their Entomophages in Conditions of the Central Forest-Steppe Zone of Ukraine. Formation of Animal and Microbic Populations in Agrosystems Pushshino, USSR. (in Russian).

Frolov NA, Bourguet D \& Ponsard S (2007) Reconsidering the taxonomy of several Ostrinia species in the light of reproductive isolation: a tale for E. Mayr. Biological Journal of the Linnean Society 91: 49-72.

Goldman N, Anderson JP \& Rodrigo AG (2000) Likelihoodbased tests of topologies in phylogenetics. Systematic Biology 49: 652-670.

Goloboff PA (1999) Analyzing large data sets in reasonable times: solutions for composite optima. Cladistics 15: 415-428.

Goloboff PA, Farris JS \& Nixon KC (2008) TNT, a free program for phylogenetic analysis. Cladistics 24: 774-786.

Grenier S, Anglade P, Naibo B, Galichet PF \& Hawlitzky N (1990) Enquête sur la répartition des tachinaires (Diptera: Tachinidae) parasitoides de la pyrale du maïs Ostrinia nubilalis 
(Lepidoptera: Pyralidae) en France (1985-1987). Entomophaga 35: 485-492.

Grillenberger BK, Gadau J, Bijlsma R, van de Zande L \& Beukeboom LW (2009) Female dispersal and isolation-by-distance of Nasonia vitripennis populations in a local mate competition context. Entomologia Experimentalis et Applicata 132: 147154.

He J-S, Chen X-X \& Ma J (2000) Fauna Sinica. Insecta, Hymenoptera, Braconidae, Vol. 18. Science Press, Beijing, China. (in Chinese).

Hebert PDN, Penton EH, Burns JM, Janzen DH \& Hallwachs W (2004) Ten species in one: DNA barcoding reveals cryptic species in the neotropical skipper butterfly Astraptes fulgerator. Proceedings of the National Academy of Sciences of the USA 101: 14812-14817.

Hu J, Zhu X-X \& Fu WJ (2003) Passive evasion of encapsulation in Macrocentrus cingulum Brischke (Hymenoptera: Braconidae), a polyembryonic parasitoid of Ostrinia furnacalis Guenée (Lepidoptera: Pyralidae). Journal of Insect Physiology 49: 367375.

Hu J, Yu XQ, Fu WJ \& Zhang WQ (2008) A Helix pomatia lectin binding protein on the extraembryonic membrane of the polyembryonic wasp Macrocentrus cingulum protects embryos from being encapsulated by hemocytes of host Ostrinia furnacalis. Developmental and Comparative Immunology 32: 356364.

Hudon M, Leroux EJ \& Harcourt DG (1989) Seventy years of European corn borer (Ostrinia nubilalis) research in North America. Agricultural Zoology Reviews 3: 53-89.

Hudson RR (2000) A new statistic for detecting genetic differentiation. Genetics 155: 2011-2014.

Hudson RR, Boos DD \& Kaplan NL (1992) A statistical test for detecting geographic subdivision. Molecular Biology and Evolution 9: 138-151.

Ji Y-J, Zhang D-X \& He LJ (2003) Evolutionary conservation and versatility of a new set of primers for amplifying the ribosomal internal transcribed spacer regions in insects and other invertebrates. Molecular Ecology Notes 3: 581-585.

Jousson O, Bartoli P \& Pawlowski J (2000) Cryptic speciation among intestinal parasites (Trematoda: Digenea) infecting sympatric host fishes (Sparidae). Journal of Evolutionary Biology 13: 778-785.

Kankare M, Stefanescu C, Van Nouhuys S \& Shaw MR (2005) Host specialization by Cotesia wasps (Hymenoptera: Braconidae) parasitizing species-rich Melitaeini (Lepidoptera: Nymphalidae) communities in north-eastern Spain. Biological Journal of the Linnean Society 86: 45-65.

Kim C-G, Hoshizaki S, Huang Y-P, Tatsuki S \& Ishikawa Y (1999) Usefulness of mitochondrial COII gene sequences in examining phylogenetic relationships in the Asian corn borer, Ostrinia furnacalis, and allied species. Applied Entomology and Zoology 34: 405-412.

Kruse JJ \& Sperling FA (2001) Molecular phylogeny within and between species of the Archips argyrospila complex (Lepidoptera: Tortricidae). Annals of the Entomological Society of America 94: 166-173.
Leliaert F, Verbruggen H, Wysor B \& De Clerck O (2009) DNA taxonomy in morphologically plastic taxa: algorithmic species delimitation in the Boodlea complex (Chlorophyta: Cladophorales). Molecular Phylogenetics and Evolution 53: 122-133.

Librado P \& Rozas J (2009) DnaSP v5: a software for comprehensive analysis of DNA polymorphism data. Bioinformatics 25: 1451-1452.

Maini S (1973) Further investigations on the parasites of Ostrinia nubilalis $\mathrm{Hb}$. (Lepidoptera, Pyralidae) in the province of Bologna. Bollettino dell'Instituto di Entomologia 'Guido Grandi' della Universita degli Studi di Bologna 32: 133-151. (in Italian).

Malausa T, Bethenod M-T, Bontemps A, Bourguet D, Cornuet J-M \& Ponsard S (2005) Assortative mating in sympatric host races of the European corn borer. Science 308: 258-260.

Malausa T, Dalecky A, Ponsard S, Audiot P, Streiff R et al. (2007) Genetic structure and gene flow in French populations of two Ostrinia taxa: host races or sibling species? Molecular Ecology 16: 4210-4222.

Manojlovic B (1984a) Results of studies on the flight of the European corn borer (Ostrinia nubilalis Hbn., Lep., Pyralidae) and its parasites. Zastita Bilja 35: 249-260. (in Serbo-Croatian).

Manojlovic B (1984b) The effectiveness of parasites in reducing populations of the European corn borer (Ostrinia nubilalis Hbn., Lep., Pyralidae) on various food plants. Zastita Bilja 35: 333-346. (in Serbo-Croatian).

Manojlovic B (1989) Distribution and importance of parasitoids of the corn borer Ostrinia nubilalis Hbn. (Lepidoptera, Pyralidae) in corn hybrids of different FAO maturity groups. Zastita Bilja 40: 115-130. (in Serbo-Croatian).

Matsubayashi KW, Ohshima I \& Nosil P (2010) Ecological speciation in phytophagous insects. Entomologia Experimentalis et Applicata 134: 1-27.

Mckoy KD, Chapuis E, Tirard C, Boulinier T, Michalakis Y, Le Bohec C, Le Maho Y \& Gautier-Clerc M (2005) Recurrent evolution of host-specialized races in a globally distributed parasite. Proceedings of the royal society B 272: 2389-2395.

Monetti L, Malvar RA, Ordàs A \& Cordero-Rivera A (2003) Parasitoids incidence and diversity on maize stem borers Sesamia nonagrioides Lefebvre and Ostrinia nubilalis Hübner in NW Spain. Maydica 48: 133-139.

Morales-Hojas R, Vieira CP \& Vieira J (2008) Inferring the evolutionary history of Drosophila americana and Drosophila novamexicana using a multilocus approach and the influence of chromosomal rearrangements in single gene analyses. Molecular Ecology 17: 2910-2926.

Mutuura A \& Munroe E (1970) Taxonomy and distribution of the European corn borer and allied species: genus Ostrinia (Lepidoptera: Pyralidae). Memoirs of the Entomological Society of Canada 71: 1-112.

Novotny V, Miller SE, Hulcr J, Drew RAI, Basset Y et al. (2002) Low beta diversity of Ostrinia herbivorous insects in tropical forests. Nature 448: 692-695.

Nylander JAA, Ronquist F, Huelsenbeck JP \& Nieves-Aldrey JL (2004) Bayesian phylogenetic analysis of combined data. Systematic Biology 53: 47-67. 
Pélissié B, Ponsard S, Tokarev YS, Audiot P, Pélissier C et al. (2010) Did the introduction of maize into Europe provide enemy-free space to $O$. nubilalis? Parasitism differences between two sibling species of the genus Ostrinia. Journal of Evolutionary Biology 23: 350-361.

Perju T (2005) Parasitoids reared from insect pests of various agrosystems. Proceedings of the Symposium 'Entomophages and their Role in the Conservation of Natural Equilibria'. University A.I. Cuza, Iaşi, Romania, pp. 47-54.

Platia G \& Maini S (1973) Studies on the insect parasites of Ostrinia nubilalis Hb. (Lepidoptera, Pyralidae) in the Forli district. Bollettino dell'Instituto di Entomologia 'Guido Grandi' della Universita degli Studi di Bologna 32: 189-202. (in Italian).

Posada D \& Crandall KA (1998) Modeltest: testing the model of DNA substitution. Bioinformatics 14: 817-818.

Posada D \& Crandall KA (2001) Intraspecific gene genealogies: trees grafting into networks. Trends in Ecology and Evolution 16: $37-45$.

Ronquist F \& Huelsenbeck JP (2003) MRBAYES 3: Bayesian phylogenetic inference under mixed models. Bioinformatics 19: 1572-1574.

Samara R, Monje JC, Reineke A \& Zebitz CPW (2008) Genetic divergence of Trichogramma aurosum Sugonjaev and Sorokina (Hymenoptera: Trichogrammatidae) individuals based on ITS2 and AFLP analysis. Journal of Applied Entomology 132: 230-238.

Shenefelt RD (1969) Braconidae, 1. Hymenopteroeum Catalogus (nova editio) 4: 1-176.

Shimodaira H \& Hasegawa M (1999) Multiple comparisons of log-likelihoods with applications to phylogenetic inference. Molecular Biology and Evolution 16: 1114-1116.

Simon C, Frati F, Beckenbach A, Crespi B, Liu H \& Flook P (1994) Evolution, weighting and phylogenetic utility of mitochondrial gene sequences and a compilation of conserved polymerase chain reaction primers. Annals of the Entomological Society of America 87: 651-702.

Sked S \& Calvin DD (2005) Temporal synchrony between Macrocentrus cingulum (Hymenoptera: Braconidae) with its preferred host, Ostrinia nubilalis (Lepidoptera: Crambidae). Environmental Entomology 34: 344-352.

Smith MA, Woodley NE, Janzen DH, Hallwachs W \& Hebert PDN (2006) DNA barcodes reveal cryptic host-specificity within the presumed polyphagous members of a genus of parasitoid flies (Diptera: Tachinidae). Proceedings of the National Academy of Sciences of the USA 103: 3657-3662.

Smith MA, Rodriguez JJ, Whitfield JB, Deans AR, Janzen DH et al. (2008) Extreme diversity of tropical parasitoid wasps exposed by iterative integration of natural history, DNA barcoding, morphology, and collections. Proceedings of the National Academy of Sciences of the USA 105: 1235912364 .

Sota T \& Vogler A (2003) Reconstructing species phylogeny of the carabid beetles Ohomopterus using multiple nuclear DNA sequences: heterogeneous information content and the performance of simultaneous analyses. Molecular Phylogenetics and Evolution 26: 139-154.

Speybroeck J \& Crochet P-A (2007) Species list of the European herpetofauna - a tentative update. Podarcis 8: 8-34.

Speybroeck J, Beukema W \& Crochet P-A (2010) A tentative species list of the European herpetofauna (Amphibia and Reptilia) - a state of the art at the end of 2009. Zootaxa 2492: 1-27.

Stephens M \& Donnelly P (2003) A comparison of bayesian methods for haplotype reconstruction from population genotype data. American Journal of Human Genetics 73: 11621169.

Stephens M, Smith N \& Donnelly P (2001) A new statistical method for haplotype reconstruction from population data. American Journal of Human Genetics 68: 978-989.

Stouthamer R, Hu J, van Kan FJPM, Platner GR \& Pinto JD (1999) The utility of internally transcribed spacer 2 DNA sequences of the nuclear ribosomal gene for distinguishing sibling species of Trichogramma. BioControl 43: 421-440.

Swofford DL (2003) PAUP ${ }^{\star}$ - Phylogenetic Analysis Using Parsimony ( ${ }^{\star}$ and Other Methods). Sinauer Associates, Sunderland, MA, USA.

Thomas Y, Bethenod M-T, Pélozuelo L, Frérot B \& Bourguet D (2003) Genetic isolation between two sympatric host-plant races of the European corn borer, Ostrinia nubilalis Hübner. I. Sex pheromone, moth emergence timing and parasitism. Evolution 57: 261-273.

Thompson WR \& Parker HL (1928) The European corn borer and its controlling factors in Europe. USDA Technical Bulletin 59: $1-62$.

Thompson JD, Gibson TJ, Plewniak F, Jeanmougin F \& Higgins DG (1997) The ClustalX windows interface: flexible strategies for multiple sequence alignment aided by quality analysis tools. Nucleic Acids Research 24: 4876-4882.

Wang RJ, Yan FM, Li SG \& Li SW (1995) Allozyme differentiation among nine populations of the corn borer (Ostrinia) in China. Biochemical Genetics 33: 413-420.

Xu M, Sun S, Wang R \& Li S (1998) Genetic variation and phylogenetic relationships among six populations of corn borers in China. Biochemical Genetics 36: 289-297.

Yang Z (1994) Estimating the pattern of nucleotide substitution. Journal of Molecular Evolution 39: 105-111.

Zhang D-X \& Hewitt GM (2003) Nuclear DNA analyses in genetic studies of populations: practice, problems and prospects. Molecular Ecology 12: 563-584. 